\title{
TECHNOPRENEURSHIP INTENTION: STUDI KASUS PADA MAHASISWA DIPENGARUHI ENTREPRENEURIAL LEARNING
}

\author{
Dwi Nurhayati, Universitas Pendidikan Indonesia \\ dwinurhayati@upi.edu \\ Amir Machmud, Universitas Pendidikan Indonesia \\ amir@upi.edu \\ Ikaputera Waspada, Universitas Pendidikan Indonesia \\ ikaputerawaspada@upi.edu
}

\begin{abstract}
ABSTRAK
Penelitian ini bertujuan untuk mengetahui dan menganalisis pengaruh entrepreneurial learning terhadap technopreneurship intention mahasiswa. Metode penelitian yang digunakan survei eksplanatori dengan pengujian hipotesis dan teknik pengumpulan data yang digunakan melalui kuesioner. Populasi penelitian yang dipilih adalah 102 mahasiswa dan sampel yang digunakan adalah sampel jenuh. Data yang terkumpul kemudian dianalisis menggunakan teknik regresi. Hasil penelitian menunjukkan bahwa secara keseluruhan entrepreneurial learning mahasiswa dikategorikan efektif dan technopreneurship intention mahasiswa dikategorikan tinggi. Diketahui bahwa variabel entrepreneurial learning berpengaruh terhadap technopreneurship intention mahasiswa. Temuan ini menyiratkan bahwa untuk meningkatkan technopreneurship intention mahasiswa, perlu untuk meningkatkan entrepreneurial learning dengan aspek learning through immersion within the industry, opportunity recognition through cultural participation, dan practical theories of entrepreneurial action.
\end{abstract}

Kata Kunci: Technopreneurship Intention, Entrepreneurial Learning.

\section{ABSTRACT}

This study aims to determine and analyze the influence of entrepreneurial learning on student's technopreneurship intention. The research method is used in an explanatory survey with hypothesis testing with the data collection technique employed through questionnaires. The study population chosen was 102 students and the sample used is a saturated sample. The collected data were then analyzed using regression techniques. The results showed that the overall entrepreneur learning of students was categorized as effective and technopreneurship intention of students were categorized as high. It is known that the entrepreneurial learning variable has influence on the student's technopreneurship intention. This finding implies that to improve student's technopreneurship intention, it is necessary to increase student's entrepreneurial learning with aspects learning through immersion within the industry, opportunity recognition through cultural participation, and practical theories of entrepreneurial action.

Keywords: Technopreneurship Intention, Entrepreneurial Learning. 


\section{PENDAHULUAN}

Masalah kompleks di negara yang sedang berkembang adalah masalah pengangguran (Saraih, et al., 2018), salah satu alasan tingginya tingkat pengangguran suatu negara adalah adanya persepsi bahwa lebih mudah untuk mencari pekerjaan di sektor formal atau non-formal sebagai karyawan dibandingkan dengan membuat lapangan pekerjaan sendiri (Indrasari, Purnomo, Syamsudin, \& Yunus, 2018). Pengangguran tidak terjadi hanya pada masyarakat pendidikan rendah tetapi terjadi pada kalangan berpendidikan tinggi juga. Lulusan dari universitas dan perguruan tinggi juga menemukan beberapa kesulitan untuk mengamankan pekerjaan mereka di sektor publik dan swasta karena lingkungan ekonomi yang bergejolak saat ini (Teshome, 2014). Faktanya dapat dilihat pada Tabel 1.

Tabel 1. Tingkat Pengangguran Terbuka Berdasarkan Tingkat Pendidikan di Indonesia Tahun 2015-2018 (dalam persen)

\begin{tabular}{lcccc}
\hline Tingkat Pendidikan & \multicolumn{4}{c}{ Tingkat Pengangguran Terbuka } \\
& Berdasarkan Tingkat Pendidikan \\
\cline { 2 - 5 } & $\mathbf{2 0 1 5}$ & $\mathbf{2 0 1 6}$ & $\mathbf{2 0 1 7}$ & $\mathbf{2 0 1 8}$ \\
\hline Tidak Pernah Sekolah & 1.25 & 1.46 & 1.63 & 2.02 \\
Sekolah Dasar & 3.94 & 3.88 & 3.61 & 2.79 \\
Sekolah Menengah & 11.16 & 9.63 & 9.48 & 7.58 \\
Sekolah Tinggi & 6.68 & 5.15 & 5.57 & 5.92 \\
\hline
\end{tabular}

Sumber: Badan Pusat Statistik, 2019.

Berdasarkan Tabel 1 menunjukkan bahwa tingkat pengangguran terbuka di Indonesia menurut tingkat pendidikan tertinggi yang ditamatkan yakni sekolah tinggi tahun 2016-2018 terus meningkat hingga mencapai 5,92\% dibandingkan tingkat pendidikan lainnya yang mengalami penurunan. Masalah yang cukup jelas terlihat adalah masih tingginya pengangguran dikalangan terdidik. Kondisi tersebut didukung pula oleh fakta bahwa sebagian besar lulusan perguruan tinggi cenderung lebih memilih sebagai mencari kerja (job seeker) daripada menciptakan lapangan pekerjaan (job creator). Hal ini kemungkinan disebabkan sistem pembelajaran yang diterapkan diberbagai perguruan tinggi saat ini masih berfokus pada sistem cepat lulus dan nilai lulus dengan cumlaude, bukan dipersiapkan kepada bagaimana mahasiswa mempunyai kecakapan pola pikir dalam menciptakan pekerjaan. Oleh karena itu, hal ini mencerminkan intensi wirausaha mahasiswa masih rendah.

Jika masalah ini terus dibiarkan maka akan berdampak para lulusan perguruan tinggi tetap banyak sebagai job seeker daripada job creator, sebagian besar lulusan masih berorientasi mencari pekerjaan dan mengalami masa tunggu kerja yang cukup lama (Handriani, 2011) hingga tingkat pengangguran Indonesia kian bertambah. Dampak secara perekonomian akan menyebabkan Indonesia sulit memperoleh keunggulan kompetitif karena peranan teknologi yang digunakan masih rendah sehingga menyebabkan produk nasional Indonesia menurun karena daya saing yang menurun. 
Pemikiran mengenai entrepreneurial intention telah berhasil dikonseptualkan dengan Theory of Entrepreneurial Event (TEE) dari Shapero \& Sokol (1982), Theory of Planned Behavior (TPB) dari Azjen (2014) dan Entrepreneurial Intention Based Models dari Francisco Linan (2004). Entrepreneurial intention merupakan manifestasi eskpresi dari dalam jiwa seseorang yang timbul dari keinginan memulai memperbaiki perekonomian diri sendiri (Suffian, Rosman, Norlaila, Norizan, \& Hasnan, 2018). Jika individu memiliki entrepreneurial intention maka dapat memperoleh keterampilan seperti pemikiran kritis, komunikasi yang efektif, dan pengambilan keputusan yang baik (Entrialgo \& Iglesias, 2017).

Perkembangan dunia usaha pun tidak dapat terlepas dari perkembangan teknologi dan ilmu pengetahuan (Handaru, Parimita, \& Mufdhalifah, 2015). Negara maju dan berkembang saat ini harus bisa menghadapi perkembangan industri yang begitu cepat dalam era keterbukaan ini (Valencia-arias, Montoya, \& Montoya, 2018). Terlebih saat ini sudah memasuki era globalisasi teknologi, dimana peluang mengambil program technopreneurial menjadi ramai. Technopreneurship dianggap penting untuk sudut pandang pembangunan sosial (Hoque, Awang, \& Siddiqui, 2017) dan sebagai upayaa meningkatkan daya saing, pertumbuhan ekonomi, dan kepentingan sosial. Oleh karena itu, akademisi sadar akan technopreneur, technopreneurship, dan niat entrepreneur dikalangan mahasiswa (Hoque, Awang, \& Siddiqui, 2017).

Technopreneurship telah dianggap sebagai cara hidup agar dapat mengatasi pengangguran di antara lulusan yang telah menjadi masalah global (Hanapi \& Nordin, 2014) sehingga lulusan didorong untuk menjadi seorang technopreneur. Technopreneurship intention membuat keadaan pikiran yang mengarahkan dan membimbing tindakan individu terhadap pengembangan, dan penerapan konsep bisnis teknologi baru (Hoque, Awang, \& Siddiqui, 2017). Intensi usaha dalam bisnis merupakan komitmen untuk melakukan suatu usaha baru dalam dunia bisnis sebagai wujud dari perilaku (Ayub, Nasip, Fabeil, \& Buncha, 2017). Untuk memulai menjadi seorang wirausaha kreatif dan efektif merupakan modal utama lahirnya seorang pengusaha untuk dapat memulai usahanya (Nguyen, 2018). Tingkat technopreneurship intention yang tinggi akan mendorong seseorang menjadi technopreneur.

Atas dasar tersebut, pentingnya Indonesia untuk terus meningkatkan technopreneurship intention karena dengan technopreneurship tidak hanya bermanfaat dalam pengembangan industri-industri besar dan canggih, tetapi juga untuk memberikan manfaat kepada masyarakat yang memiliki kemampuan ekonomi lemah dan untuk meningkatkan kualitas hidup mereka. Dengan demikian, technopreneurship diharapkan dapat mendukung pembangunan berkelanjutan (sustainable development) (LP2KHA, 2015).

Secara garis besar, intensi berwirausaha dipengaruhi oleh faktor internal, eksternal, dan kontekstual (Asma, Rosdi, Amri, Adnan, \& Samsudin, 2018). Faktor internal berasal dari dalam diri dapat berupa karakter, sifat, ciri-ciri kepribadian (self-efficacy) (Bayron, \& Ed, 2013; Luis \& Campo, 2010), pengambilan resiko, kebutuhan untuk berprestasi, sikap terhadap kewirausahaan, kontrol perilaku (Remeikiene, Startiene, \& Dumciuviene, 2013) maupun faktor sosio-demografi. Sedangkan faktor eksternal berasal dari luar diri pelaku entrepreneur yang dapat berupa unsur dari lingkungan sekitar 
(Sadeghi, Mohammadi, Nosrati, \& Malekian, 2013), dan kondisi kontekstual (Mahajan \& Arora, 2018; Kristiansen \& Nurulindarti, 2014).

Beberapa penelitian mengenai technopreneurship intention telah dilakukan oleh peneliti seperti (Hoque, Awang, \& Siddiqui, 2017) mengenai entrepreneur self-efficacy, technopeurial learning terhadap technopeurial intention. (Baradaran, $\mathrm{dkk}, 2019)$ mengenai competencies of technology entrepreneur. (Singhry, 2015) mengenai technology entrepreneurship capabilities, knowledge-sharing capabilities terhadap technopreneurship intention. (Chou, Shen, \& Hsiao, 2011) mengenai self-efficacy, entrepreneurial intention terhadap entrepreneurial learning behavior. (Nathalie et al., 2010) mengenai pembelajaran kewirausahaan terhadap technopreneurship intention. Technopreneurship kerap kali sebagai jargon yang mewakili penggabungan teknologi dengan keterampilan kewirausahaan (Selladurai, 2016). Sederhananya, seorang technopreneur adalah wirausaha yang menggunakan teknologi untuk tujuan kewirausahaan. Atas dasar tersebut, peneliti bertujuan untuk mengetahui pengaruh entrepreneur learning terhadap technopreneurship intention.

Berdasarkan Theory of Entrepreneurial Event (TEE) yang dikemukakan oleh Shapero \& Sokol (1982) terdapat dua jenis persepsi yang mempengaruhi intensi berwirausaha, yaitu 1) perceived desirability, mengacu pada sejauh mana dia merasa tertarik terhadap perilaku tertentu (untuk menjadi pengusaha), dan 2) perceived feasibility, mengacu pada sejauh mana orang menganggap bahwa dirinya sendiri mampu melaksanakan perilaku tertentu. Model intensi kewirausahaan juga dijelaskan oleh Theory of Planned Behavior dari Icek Ajzen (2014) bahwa determinan utama dari intensi dan perilaku dapat dijelaskan dengan belief behavioral, belief normatif, dan belief control. Variabel-variabel lain yang mungkin berhubungan atau mempengaruhi belief individu antara lain usia, gender, etnis, status sosial, ekonomi, pendidikan, kebangsaan, agama, kepribadian, mood, emosi, sikap, dan nilai yang bersifat umum, intelegensi, pengalaman masa lalu, dan dukungan sosial. Determinandeterminan ini menjadi background factors yang mampu dijelaskan dengan logika.

Entrepreneurial Intention-based Models merupakan model yang dirancang untuk mendeteksi faktor-faktor yang mempengaruhi intensi kewirausahaan dengan menggunakan pendekatan pendidikan. Model ini didesain oleh Francisco Linan dari Universitas Sevilla, Spanyol. Model ini dibuat berdasarkan dua teori, yaitu Theory of Planned Behavior (TPB) yang dikemukakan oleh Ajzen (2014) dan Theory of Entrepreneurial Event (TEE) yang disampaikan Shapero \& Sokol (1982), sehingga muncul konsep Entrepreneurial Intention-based Models (Iskandar, 2012).

Entrepreneurial Intention-based Models yaitu intensi seseorang untuk berwirausaha dipengaruhi oleh beberapa faktor yaitu personal atittude, perceived social norms, dan perceived feasibility/self-efficacy. Ketiga faktor tersebut dipengaruhi oleh pengetahuannya tentang kewirausahaan. Pengetahuan kewirausahaan yang secara signifikan mempengaruhi keputusan dalam penciptaan usaha. Menurut Linan \& Fayolle (2015) pengetahuan yang lebih banyak tentang kewirausahaan tentu akan berkontribusi dalam menumbuhkan intensi berwirausaha, kemudian berkontribusi terhadap 
munculnya sikap positif tentang kewirausahaan, hingga berpengaruh terhadap persepsi yang lebih realistis tentang kewirausahaan dan akan meningkatkan keyakinan atau kepercayaan diri bahwa individu tersebut layak dan mampu untuk menjadi seorang wirausaha.

Dimensi lain dari intensi didasarkan kepada empat dimensi diantaranya (Handaru, et al., 2015) yaitu:

1. Desires, adalah sesuatu dalam diri seseorang yang berupa keinginan atau hasrat yang tinggi untuk memulai suatu usaha.

2. Preferences, adalah sesuatu dalam diri seseorang yang menunjukkan bahwa memiliki usaha atau bisnis yang mandiri adalah suatu kebutuhan yang harus dicapai.

3. Plans, merujuk pada harapan dan rencana yang ada dalam diri seseorang untuk memulai suatu usaha di masa yang akan datang.

4. Behavior Expectancies, adalah tinjauan atas suatu kemungkinan untuk berwirausaha dengan diikuti oleh target dimulainya sebuah usaha bisnis.

Merujuk pada model Entrepreneurial Intention-based Models bahwa pengetahuan akan kewirausahaan berperan terhadap intensi seseorang untuk berwirausaha. Berdasarkan teori Kolb (2014), entrepreneurial learning dapat dianggap sebagai proses pengalaman dimana para technopreneur mengembangkan pengetahuan melalui empat kemampuan belajar yang berbeda yaitu mengalami, merefleksikan, berpikir, dan bertindak. Entrepreneurial learning merupakan instrumen efektif guna menanamkan atau menginternalisasikan tidak saja persepsi, tetapi juga efikasi diri, intensi dan kompetensi berwirausaha (Rahmadani, Suwatno, Machmud, 2018).

Dapat disimpulkan bahwa entrepreneurial learning sebagai proses memperoleh pengetahuan, keterampilan, dan sikap berwirausaha yang berkelanjutan untuk proses penciptaan dan pengelolaan menjadi technopreneur yang efektif. Penelitian sebelumnya telah mengungkapkan indikasi faktor kontekstual seperti program pendidikan dapat meningkatkan niat kewirausahaan serta entrepreneur (Nathalie et al., 2010). Model pembelajaran kewirausahaan (Rae, 2015) mengungkapkan adanya contextual learning yang mempengaruhi pribadi seseorang. Pembelajaran kewirausahaan dipengaruhi oleh kehidupan pribadinya dan pengalaman keluarga, oleh pendidikan, karier profesional dan hubungan sosial. Dengan cara ini, komponen personal dan pembentukan sosial mempengaruhi kapasitas belajar dan pengetahuan yang diperoleh (Paiva, et al, 2019). Hipotesis yang akan diajukan dalam penelitian ini menggambarkan pengaruh entrepreneurial learning terhadap technopreneurship intention. Model penelitian yang diajukan oleh peneliti ditunjukkan pada Gambar 1.

\begin{tabular}{|c|c|}
\hline $\begin{array}{c}\text { Entrepreneurial } \\
\text { Learning }(\mathrm{X})\end{array}$ & $\begin{array}{c}\text { Technopreneurship } \\
\text { Intention }(\mathrm{Y})\end{array}$ \\
\hline
\end{tabular}

Gambar 1. Hubungan antara Entrepreneurial Learning dengan Technopreneurship Intention 


\section{METODE PENELITIAN}

Jenis penelitian yang digunakan adalah penelitian deskriptif, verifikatif dengan metode survey eksplanatori dan teknik pengumpulan data melalui penyebaran kuesioner kepada mahasiswa pascasarjana pendidikan ekonomi UPI Bandung. Penelitian ini dilakukan dalam kurun waktu kurang dari satu tahun, maka metode yang digunakan yaitu cross sectional method. Untuk mengukur technopreneurship intention indikator yang digunakan mengacu kepada riset (Handaru et al., 2015) yaitu preferences, plans, desires, dan behavior expectations. Pengukuran entrepreneurial learning menggunakan indikator yang mengacu pada riset model (Rae, 2015) yaitu learning through immersion within the industry, opportunity recognition through cultural participation, dan practical theories of entrepreneurial action.

Populasi penelitian ini adalah seluruh mahasiswa pascasarjana pendidikan ekonomi UPI Bandung yang berjumlah 102 mahasiswa. Sampel yang digunakan adalah sampel jenuh dimana sampel pada penelitian ini mengambil seluruh mahasiswa atau populasi. Gambaran responden berdasarkan jenis kelamin sebanyak 69 mahasiswa perempuan dan 33 mahasiswa laki-laki. Data yang telah terkumpul dianalisis dengan menggunakan sistem skoring skala likert 5 poin dari sangat tidak setuju hingga sangat setuju untuk mendapatkan data interval dan diberi skor atau nilai. Faktor yang mempengaruhi technopreneurship intention digunakan model regresi dengan persamaan berikut :

$$
\begin{aligned}
& \mathrm{Y}=\mathrm{a}+\mathrm{b}_{1} \mathrm{X}_{1}+\mathrm{e} . \\
& \text { Keterangan: } \\
& \mathrm{Y}: \text { Technopreneurship intention } \\
& \mathrm{X} \text { : Entrepreneur learning } \\
& \mathrm{e}: \text { Faktor penganggu }
\end{aligned}
$$

\section{HASIL PENELITIAN DAN PEMBAHASAN}

Variabel pada penelitian ini yaitu entrepreneurial learning dan technopreneurship intention. Deskripsi hasil penelitian didasarkan pada perhitungan skor dari setiap jawaban responden, sehingga diperoleh hasil skor jawaban responden. Gambaran umum mengenai tingkat entrepreneurial learning dan tingkat technopreneurship intention diperoleh dari hasil angket penelitian yang terdiri dari 20 item pernyataan, berikut hasil pada mahasiswa pascasarjana pendidikan ekonomi UPI Bandung dapat dilihat pada Tabel 2.

Berdasarkan hasil penelitian yang telah dilakukan bahwa gambaran umum tingkat entrepreneurial learning berada pada kategori efektif dan tingkat technopreneurship intention berada pada kategori tinggi. Hal ini menandakan bahwa tingkat entrepreneurial learning yang telah dilakukan mahasiswa sudah efektif sehingga memiliki tingkat technopreneurship intention yang tinggi. Analisis data menggunakan regresi linier dengan bantuan SPSS 25. Hal itu untuk mengetahui seberapa besar pengaruh entrepreneurial learning terhadap technopreneurship intention mahasiswa. 
Tabel 2. Gambaran Umum Tingkat Entrepreneurial Learning dan Technopreneurship Intention Mahasiswa UPI Tahun 2019

\begin{tabular}{|c|c|c|}
\hline Variabel & Mean & Kategori \\
\hline \multicolumn{3}{|c|}{ Entrepreneurial Learning } \\
\hline $\begin{array}{l}\text { Learning through immersion } \\
\text { within the industry }\end{array}$ & 3,30 & Efektif \\
\hline $\begin{array}{l}\text { Opportunity recognition } \\
\text { through cultural participation }\end{array}$ & 3,10 & Cukup efektif \\
\hline $\begin{array}{l}\text { Practical theories of } \\
\text { entrepreneurial action }\end{array}$ & 4,25 & Sangat efektif \\
\hline Rata-rata & 3,55 & Efektif \\
\hline \multicolumn{3}{|c|}{ Technopreneurship Intention } \\
\hline Preference & 4,05 & Tinggi \\
\hline Plan & 3,67 & Tinggi \\
\hline Desire & 4,12 & Tinggi \\
\hline Behavior expectation & 3,51 & Tinggi \\
\hline Rata-rata & 3,84 & Tinggi \\
\hline
\end{tabular}

Tabel 3. Coefficients

\begin{tabular}{|c|c|c|c|c|c|}
\hline \multirow{2}{*}{ Model } & \multicolumn{2}{|c|}{$\begin{array}{l}\text { Unstandardized } \\
\text { Coefficients }\end{array}$} & \multirow{2}{*}{$\begin{array}{c}\text { Standardized } \\
\text { Coefficients } \\
\text { Beta }\end{array}$} & \multirow[b]{2}{*}{$t$} & \multirow[b]{2}{*}{ Sig. } \\
\hline & B & $\begin{array}{l}\text { Std. } \\
\text { Error }\end{array}$ & & & \\
\hline (Constant) & 5,666 & 3,289 & & 1,723 & 0,000 \\
\hline EL & 0,366 & 0,097 & 0,532 & 3,782 & 0,000 \\
\hline
\end{tabular}

Tabel 4. Model Summary

\begin{tabular}{ccccc}
\hline Model & $\mathbf{R}$ & $\begin{array}{c}\mathbf{R} \\
\text { Square }\end{array}$ & $\begin{array}{c}\text { Adjusted } \\
\text { R Square }\end{array}$ & $\begin{array}{c}\text { Std. Error of } \\
\text { the Estimate }\end{array}$ \\
\hline 1 & 0,746 & 0,557 & 0,551 & 1,532 \\
\hline
\end{tabular}

Berdasarkan Tabel 3 dan 4, dapat disusun sebuah model persamaan regresi linier yaitu $\mathrm{Y}=5,66+0,366 \mathrm{X}_{1}+0,443 \mathrm{e}$

Berdasarkan hasil persamaan tersebut, dapat diketahui bahwa

1. Konstanta sebesar 5,66 artinya jika tidak ada perubahan dari variabel entrepreneurial learning maka besarnya technopreneurship intention adalah 5,66.

2. Koefisien regresi untuk variabel entrepreneurial learning sebesar 0.366 dengan arah positif, artinya setiap penambahan nilai variabel entrepreneurial learning maka akan menyebabkan peningkatan terhadap variabel technopreneurship intention.

Untuk melihat seberapa besar pengaruh dari variabel entrepreneurial learning terhadap technopreneurship intention dapat dilihat pada Tabel 4, diketahui bahwa hasil koefisien determinasi (R2) menunjukkan sebesar 0,557 artinya bahwa variabel entrepreneurial learning berpengaruh terhadap 
technopreneurship intention sebesar $55,7 \%$ dan sisanya sebesar $44,3 \%$ dipengaruhi oleh variabel lain yang tidak dijelaskan dalam model penelitian ini. Pengujian hipotesis penelitian ini menggunakan ANOVA uji F, didapatkan nilai $\mathrm{F}$ hitung sebesar 3,872 maka dari hasil yang didapatkan bahwa $\mathrm{F}$ hitung $(3,872)>\mathrm{F}$ tabel $(1,655)$, dan nilai signifikansi $0,000<$ nilai $\alpha 0,05$. Oleh karena itu, dapat disimpulkan bahwa entrepreneurial learning berpengaruh positif dan signifikan terhadap technopreneurship intention.

Entrepreneurial learning berhubungan positif terhadap technopreneurship intention yang memiliki arti bahwa semakin tinggi tingkat entrepreneurial learning maka akan semakin tinggi pula tingkat technopreneurship intention mahasiswa. Entrepreneurial learning memberikan perpaduan antara pengalaman belajar, pengembangan keterampilan, dan yang paling penting perubahan pola pikir. Oleh karena itu, semakin banyak pengetahuan kewirausahaan yang didapatkan akan merubah pola pikir mahasiswa untuk berniat menjadi technopreneur. Hasil ini sejalan dengan penelitian sebelumnya seperti yang telah diungkapkan bahwa indikasi faktor kontekstual seperti program pendidikan dapat meningkatkan niat kewirausahaan serta entrepreneur (Nathalie et al., 2010). Seperti halnya (Hoque, Awang, \& Siddiqui, 2017) bahwa entrepreneurial learning memiliki hubungan positif dengan technopreneurship intention, dimana entrepreneurial learning memediasi hubungan antara entrepreneurial self-efficacy dan technopreneurship intention.

Entrepreneurial learning yang dikaji pada penelitian ini adalah dilihat dari tiga dimensi yaitu tingkat kemampuan belajar melalui pengalaman, tingkat memanfaatkan peluang melalui penciptaan dan berbagi konteks sosial dan budaya serta tingkat pemahaman teori praktis aksi wirausaha. Merujuk Kolb (2014) bahwa pembelajaran kewirausahaan dapat dianggap sebagai proses pengalaman dimana para technopreneur mengembangkan pengetahuan melalui empat kemampuan belajar yang berbeda yaitu mengalami, merefleksikan, berpikir, dan bertindak. Selain itu, teori pembelajaran sosial dari Bandura mendasarkan pada asumsi interaksi triadic reciprocality bahwa belajar merupakan proses perubahan tingkah laku yang akan menghasilkan kepribadian yang baik, sehingga dapat dikatakan bahwa tingkah laku manusia merupakan hasil interaksi timbal balik yang terus menerus antara faktor internal dan eksternal (lingkungan) (Bandura, 2010).

Pembelajaran kontekstual berkaitan dengan bagaimana kemampuan mahasiswa dapat belajar melalui pengalaman kewirausahaan yang telah didapatkan selama ini, baik pengalaman pribadi maupun pengalaman orang lain. Kemampuan mengambil peluang melalui penciptaan dan konteks sosial budaya disekitarnya, dengan bagaimana mahasiswa dapat menciptakan peluang usaha ditengah situasi yang terjadi tanpa mengesampingkan aspek sosial dan budayanya. Pemahaman teori praktis kewirausahaan berkaitan dengan pendidikan kewirausahaan yang telah didapatkan seperti mengikuti mata kuliah kewirausahaan. Hasilnya menunjukkan bahwa pembelajaran kewirausahaan efektif untuk meningkatkan technopreneurship intention mahasiswa.

Pembelajaran kontekstual terjadi ketika individu melaporkan dan membandingkan pengalaman, menciptakan dan berbagi, dalam konteks sosial dan budaya dan dalam jaringan hubungan mereka. Melalui hubungan sosial ini 
dan berbagai situasi dan konteks, individu belajar dan mengembangkan peluang keterampilan pengakuan. Pertukaran ide dan tujuan interaktif ini dengan individu lain disebut sebagai perusahaan yang dinegosiasikan, pertukaran ini dilakukan dalam konteks bisnis dengan pelanggan, pemasok, investor, karyawan, atau mitra. Dimensi ini dibagi menjadi empat yaitu makna bersama, struktur dan praktik, perubahan peran dari waktu ke waktu, dan penyisipan dalam jaringan hubungan eksternal (Paiva, et al, 2019).

Hasil penelitian (Hoque, Awang, Siddiqui, 2017) self-efficacy technopreneurial mendorong individu untuk mencari ilmu dalam mencapai tujuan. Penelitian menunjukkan bahwa self-efficacy technopreneurial penting untuk mempengaruhi hasil technopreneurial learning. Akibatnya, paparan technopreneurial learning akan membantu untuk memahami technopreneurship lebih baik dan sangat penting untuk meningkatkan selfefficacy technopreneurial khususnya untuk mempromosikan kompetensi technopreneur (Hmieleski \& Baron, 2008), sehingga akan untuk memperkuat technopreneurship intention.

Hasil penelitian ini menunjukkan bahwa tingkat technopreneurship intention mahasiswa sudah berada dikategori tinggi. Hal ini mengisyaratkan bahwa semakin banyak mahasiwa belajar kewirausahaan maka kesadaran untuk menjadi technopreneur akan semakin terbangun lebih kuat. Kemampuan kombinasi antara pengetahuan kewirausahaan dan teknologi adalah syarat menjadi technopreneur. Technopreneurship harus memiliki keunggulan terhadap teknologi, hal ini dapat diciptakan melalui kreativitas dan inovasi untuk menyokong pengembangan unit usaha. Pada dasarnya, kunci kewirausahaan adalah adanya kreatif dan inovatif maka kreativitas dan inovasi dalam pemanfaatan teknologi dengan tepat adalah hal utama dalam mengembangkan jiwa technopreneurship.

\section{SIMPULAN}

Berdasarkan hasil pengolahan dan analisis data, maka dapat ditarik kesimpulan bahwa tingkat entrepreneurial learning mahasiswa berada pada kategori efektif dan tingkat technopreneurship intention berada pada kategori tinggi. Variabel entrepreneurial learning memiliki pengaruh positif dan signifikan terhadap technopreneurship intention sebesar 55,7\%. Temuan ini menunjukkan bahwa hipotesis entrepreneurial learning memiliki pengaruh positif dan signifikan terhadap technopreneurship intention terbukti benar. Hal ini menunjukkan bahwa tingkat entrepreneurial learning yang tinggi akan mempengaruhi technopreneurship intention yang lebih baik, sehingga ilmu pengetahuan yang dimiliki akan semakin luas.

Berdasarkan hasil temuan dalam kajian ini, maka peneliti memberikan rekomendasi sebagai berikut:

1. Bagi perguruan tinggi, diharapkan dapat menerapkan kurikulum berbasis kompetensi berorientasi technopreneur. Perguruan tinggi mampu memberikan bekal setiap mahasiswa berupa soft skill maupun hard skill mengenai kewirausahaan agar technopreneurship intention mahasiswa meningkat tidak terfokus pada job seeker. 
2. Bagi mahasiswa, diharapkan dapat mengembangkan kapasitas dirinya melalui entrepreneurial learning, seperti mengikuti mata kuliah kewirausahaan dengan baik, training kewirausahaan, magang, berorganisasi, dan lain-lain.

3. Bagi peneliti selanjutnya, diharapkan dapat mengembangkan lebih dalam terkait permasalahan yang mempengaruhi entrepreneurial learning dan technopreneurship intention mahasiswa.

\section{DAFTAR RUJUKAN}

Ajzen, Icek. (2014). The Theory of Planned Behaviour is Alive and Well, and Not Ready to Retire: A Commentary on Sniehotta, Presseau, and AraújoSoares. Health Psychology Review, 9(2), 131-137.

Asma, S., Rosdi, M., Amri, A., Adnan, Z., \& Samsudin, N. (2018). Intention towards Business Start-Up among Orang Asli in Peninsular Malaysia Intention towards Business Start-Up among Orang Asli in Peninsular Malaysia, 8(5), 945-961.

Ayub, M. S., Nasip, S., Fabeil, N. F., \& Buncha, M. R. (2017). Entrepreneurial Intention Among Students: A Study In Bulungan Tarakan, Indonesia, $345-356$.

Badan Pusat Statistik. (2019). Tingkat Pengangguran Terbuka Berdasarkan Tingkat Pendidikan di Indonesia Tahun 2015-2018 (dalam persen).

Bandura, A. (2010). Self-efficacy. The Corsini Encyclopedia of Psychology, 1-3.

Bayron, C. E., \& Ed, D. (2013). Social Cognitive Theory, Entrepreneurial SelfEfficacy and Entrepreneurial Intentions: Tools to Maximize the Effectiveness of Formal Entrepreneurship Education and Address the Decline in Entrepreneurial Activity, 6(1), 66-77.

Baradaran, M. Sagedh., Farsi, Hejazi, \& Akbari. (2019). A Competency-based Typology of Technology Entrepreneurs: A Systematic Review of the Empirical Studies. Iranian Journal of Management Studies (IJMS), 12(2), 191-211.

Chun-Mei, Chou., Shen Chien-Hua, Shen., \& Hsi-Chi, Hsia. (2011). The Influence of Entrepreneurial Self-Efficacy on Entrepreneurial Learning Behavior - Using Entrepreneurial Intention as the Mediator Variable. International Business and Management, 3(2), 7-11.

Entrialgo, M., \& Iglesias, V. (2017). Are the Intentions to Entrepreneurship of Men and Women Shaped Differently? The Impact of Entrepreneurial Role-Model Exposure and Entrepreneurship Education. Entrepreneurship Research Journal, 8(1), 1-14. 
Hanapi, Z. \& Nordin, M. S. (2014). Unemployment among Malaysia Graduates: Graduates' Attributes, Lecturers' Competency and Quality of Education. International Conference on Education \& Educational Psychology 2013 (ICEEPSY 2013), 112 (7), 1056-1063.

Handaru, A. W., Parimita, W., \& Mufdhalifah, I. W. (2015). Membangun Intensi Berwirausaha Melalui Adversity. Jurnal Manajemen dan Kewirausahaan, 17(2), 155-166.

Handriani, Eka. (2011). Pengembangan Kualitas Pendidikan Kewirausahaan di Perguruan Tinggi. Jurnal Ilmiah Inkoma, 22(1), 83-95.

Hmieleski, K. M., \& Baron, R. A. (2008). When Does Entrepreneurial Self-efficacy Enhance Versus Reduce Firm Performance?. Strategic Entrepreneurship Journal, 2(1), 57-72.

Hoque, Awang, Siddiqui. (2017). Entrepreneur Intention Among University Students of Business Courses in Malaysia: A Structural Equation Modeling. International Journal of Entrepreneurship and Small \& Medium Enterprise (IJSME), 4, 1-16.

Indrasari, M., Purnomo, R. B., Syamsudin, N., \& Yunus, E. (2018). Development Entrepreneurship Intention Among Students. International Journal of Entrepreneurship and Business Development, 1(2), 146-154.

Iskandar. (2012). Efektifitas Pendidikan Kewirausahaan dalam Mengembangkan Jurnal Pendidikan Vokasi, 2(3).

Kolb, D. A. (2014). Experiential Learning: Experience as the Source of Learning and Development. FT Press.

Lembaga Pengembangan Pendidikan, Kemahasiswaan, dan Hubungan Alumni (LP2KHA). (2015). Technopreneurship. Institut Teknologi Sepuluh November (ITS).

Liñán, F., \& Fayolle, A. (2015). A Systematic Literature Review on Entrepreneurial Intentions: Citation, Thematic Analyses, and Research Agenda. International Entrepreneurship and Management Journal, 11(4), 907-933.

Liñán, F. (2004). Intention-based Models of Entrepreneurship Education. Piccolla Impresa/Small Business, 3(1), 11-35.

Luis, J., \& Campo, M. (2010). Analysis of the Influence of Self-Efficacy on Entrepreneurial Intentions, 14-21. 
Mahajan, T., \& Arora, V. (2018). Analysis of Autonomy Factor of Entrepreneurship Intention with Reference to Students of Selected Universities of North-India, 20(2), 87-91.

Nathalie, Duval-Couetil, Teri Reed-Rhoads, \& Shiva Haghighi. (2010). Investigating the Impact of Entrepreneurship Education on Engineering Students. Peer-reviewed Paper Presented at NCIIA 2010, Washington, DC.

Nguyen, C. (2018). Demographic Factors, Family Background and Prior SelfEmployment on Entrepreneurial Intention - Vietnamese Business Students Are Differen: Why?. Nguyen Journal of Global Entrepreneurship Research, 8(1), 10.

Paiva, et al. (2019). Impact's Perception of Entrepreneurship Competences Acquisition in Polytechnic High Education Students. A volume in the Advances in Business Strategy and Competitive Advantage (ABSCA) Book Series. United States of America by IGI Global, 179-201.

Rae, D., \& Wang, C. L. (2015). Entrepreneurial Learning: Past Research and Future Challenges. In Entrepreneurial Learning. Routledge. 25-58.

Rahmadani., Suwatno., \& Machmud, A. (2018). Analisis Faktor-Faktor yang Mempengaruhi Pendidikan Kewirausahaan (Entrepreneurship Education) di Perguruan Tinggi Negeri Kota Bandung. SOSIO DIDAKTIKA: Social Science Education Journal, 5(1), 47-53.

Remeikiene, R., Startiene, G., \& Dumciuvience, D. (2013). Explaining Entrepreneurial Intention of University Students: The Role of Entrepreneurial Education, 299-307.

Sadeghi, M., Mohammadi, M., Nosrati, M., \& Malekian, K. (2013). The Role of Entrepreneurial Environments in University Students Entrepreneurial Intention. World Applied Programming, 3(8), 361-366.

Saraih, U., Zin Aris, A. Z., Abdul Mutalib, S., Tunku Ahmad, T. S., Abdullah, S., \& Harith Amlus, M. (2018). The Influence of Self-Efficacy on Entrepreneurial Intention among Engineering Students. MATEC Web of Conferences, 150, 05051.

Selladurai, M. (2016). Conceptual Framework of Technopreneurship. SELP Journal of Social Science, 7(27), 92-97.

Shapero, A., \& Sokol, L. (1982). The Social Dimensions of Entrepreneurship. Encyclopedia of Entrepreneurship, 72-90. 
Singhry, Hassan Barau. (2015). The Effect of Technology Entrepreneurial Capabilities on Entrepreneur Intention of Nascent Graduates. European Journal of Business and Management, 7(34), 8-20.

Suffian, M. Z. A., Rosman, M., Norlaila, I., Norizan, A., \& Hasnan, M. T. (2018). Entrepreneurial Intention: An Empirical Study Among Undergraduate Students. Journal of Fundamental and Applied Sciences, 10(2S), 413-435.

Teshome, T. (2014). Attitudes of Private Higher Education Students Towards Entrepreneurship: A Case of Distance Learners in Wolaita Sodo and Hossana Towns. MiddleEast Journal of Scientific Research, 19(2), 277285.

Valencia-arias, A., Montoya, I., \& Montoya, A. (2018). Constructs and Relationships in the Study of Entrepreneurial Intentions in University Students, International Journal of Environmental \& Science Education, 13(1), 31-52. 
